\title{
Postgraduate nursing students' acquire skills upon applying problem based learning
}

\author{
Sahar Mohamed Soliman ${ }^{1}$, Samia M. Abd El -Mouty, ${ }^{2}$, \\ Nagwa Mahmoud Salem ${ }^{3}$ \\ 1(Assist. Professor of Community Health Nursing, Faculty of Nursing, Mansoura University, Egypt). \\ 2(Lecturer of community health nursing Faculty of Nursing, Mansoura University, Egypt) \\ 3(Lecturer of community health nursing Faculty of Nursing, Mansoura University, Egypt)
}

\begin{abstract}
:
Background: Problem based learning (PBL) is an effective strategy of self- directed learning. It focuses on delivering instruction in which problems are used as the basis of learning. Teaching approaches of higher education is continuously upgrading in Egypt. Although some Egyptian universities have adopted PBL as a learning method for undergraduate students, they did not adopt it as a learning method for postgraduate students.

Objective: This study sought to describe the attainable skills of applying problem based learning strategy among postgraduate nursing student.

Study design: Cross- sectional study design was used to describe the outcomes of introducing problem-based learning as educational strategy to Community studies and allied health problems' Course. All the 68 postgraduate students nursing who were registered for master during the academic year 2014/2015 involved in the study. Four students' evaluation tools were used in this study to evaluate the different acquired skills and their opinions regarding PBL. The evaluation tools included tutor evaluation scale, self-evaluation scale, peer evaluation and students' opinion scale.

Results: The study revealed that (50\%) of students showed very good level in achieving the groups learning goals by tutor evaluation and obtained adequate information about the problem by self-evaluation. While (54.4\%) showed responsibility and commitment by peer evaluation and (88.2\%) were strongly agree that this method is effective than lecture.

Conclusion: The main conclusion drawn from the current study is that the majority of the postgraduate students were strongly agreed that problem based learning strategy is more effective than traditional learning strategy.

Keywords: Problem-based learning - Community health nursing - Postgraduate students' experience
\end{abstract}

\section{Introduction}

Education today is changing from one of factual based to one of inquiry based. This approach of learning is bringing about new ways in which students are involved in the learning process. Teachers knew that students receive knowledge passively and do not learn at their highest potential when they are in a classroom ${ }^{(1,}$ ${ }^{2)}$. Learning process will be more effective when instructors take the role of facilitator, coach and mentor to guide students during the problem solving process in state of teach and provide the answer to the problem. Problem-Based Learning (PBL) in the student centered classroom gives students the chance to learn best and to discover knowledge in a meaningful and applicable way ${ }^{(3)}$. Moreover, Smith-Goodwin, and Jeffrey ${ }^{(4)}$ reported that PBL, provide students with learning opportunities for "how to think" rather than "what to think," and potentially within the framework of sustainability.

Nowadays, PBL in nursing field is an instructive strategy that was approved by World Medical Educational and World Health Organization (WHO), as an efficient technique of training community oriented students. Nursing students will be proficient in using theoretical knowledge in their working life if they acquired decision-making abilities, creativity, and sense of responsibility ${ }^{(5)}$. The Nursing Education Society in Egypt face a challenge in preparing students to execute nursing roles within the context of integrated health care system $^{(6)}$. Therefore, some nursing programs are using PBL to assist students in developing higher level of skills associated with professional nursing practice ${ }^{(7)}$. PBL is a student-centered learning approach which strongly influence students behavior and enables them to work cooperatively in small group of 6-10 students for seeking solutions to situations or problems ${ }^{(7,8)} \mathrm{PBL}$ approach is depending on providing trigger material to a group of students, who asked to analyze the problem based on acquired knowledge. The trigger is a brief and broad statement of a individual, groups or community problem that used to stimuli clarifying the included concepts. Then students formulate their learning goals to find solution of the problem. These processes allow students to work cooperatively with the facilitator and with colleagues ${ }^{(9,10)}$. PBL shows student that learning can take place anywhere and at any time. In addition, PBL teaches students to use the information in a meaningful and 
productive way ${ }^{(8)}$. Community and population health courses are introduced to health profession programs including postgraduate nursing programs. In such courses nursing student require to integrate theories with practice, which can be achieved by active self- learning rather than conventional learning. The ability of nurses to become self- directed learner is one way of ensuring the continuous competency upgrading in- field practice (11)

The Egyptian agenda for higher education focused on the importance of considering the needs and students' performance in developing curricula ${ }^{(12)}$. The curricula that adopt of PBL equip students with professional, life-long learning skills that emphasis on application of knowledge, problem solving, and selfdirected learning skills. In addition, it helps students to retain information much longer and better than traditional educational methods ${ }^{(13)}$. However, there has been little research on postgraduate students' experiences with PBL. Using of PBL as a educational strategy for postgraduate students in "community studies and allied health problems" course was innovated. Therefore, it was important to conduct the current study; to describe the postgraduate nursing students' acquired skills upon applying problem based learning

\section{Aim Of The Study}

The study aimed to describe the postgraduate nursing students' acquired skills upon applying problem based learning.

\section{Subjects \& Methods}

3.1-Study design: Cross- sectional study design was used to describe the outcomes of introducing problembased learning as educational strategy.

3.2- Research questions:

1. What are the acquired skills among postgraduate nursing student as outcomes of experiencing problem- based learning?

2. What are the opinions of postgraduate nursing student regarding problem- based learning as educational strategy?

\section{3- Study Setting}

The study was conducted at Faculty of Nursing Mansoura University.

\section{4-Subjects and Sampling}

Convenient sampling technique was used to recruit subjects that involved all master nursing students $(n=68)$ who registered at the post graduate preparatory courses and studying the course of "Community studies and allied health problems" during academic year 2014-2015

\section{5-Tools of the study}

Data were collected by using the following tools:

Tool I: Problem based learning module:

Based on the literature review the problem based learning module was developed by researchers included 9 scenarios related to Community studies and allied health problems

Tool II- Students' performance evaluation:

This scale was adopted from Criterion- Referenced System that developed by Montemayor $2004{ }^{(14)}$. This scale was used by tutor to evaluate certain criteria of master students' performance and abilities throughout the problem- based sessions (PBL). Students also used the same scale for self- evaluation. The evaluation scale is a 6-point likert scale that starts with "not developed skills" to end by "excellent level of performance". This scale consisted of four parts namely; reasoning and decision-making skills, self- learning, collaborative work skills and personal characteristics and commitment.

\section{Tool III- Students' opinion scale:}

The opinion scale was developed by the researchers to obtain the opinion of the postgraduate students regarding to the PBL sessions. The opinion scale is a 5- point likert scale starts with "strongly disagree" to "strongly agree". This scale included four parts namely; skills that are provided by the PBL, the facility, resources and the structure of the learning materials.

Tool IV- Peer evaluation scale

This tool was modified form of the scale of Montemayor $2004^{(14)}$. and used to evaluate students' performance by their peers throughout problem-based learning sessions

\section{6-Methods:}

1- Ethical consideration:

1- The Community Health Nursing Department Committee approved to apply problem- based learning as a educational strategy in the course of "community studies and allied health problems".

2-Approval was obtained from the Research Ethics Committee, Faculty of Nursing.

3- Postgraduate students were informed about the study in the beginning of the course. They were ensured that their participation and their opinions about the course would have no effect on their academic evaluation. Researchers assured that all questionnaires were anonymous and considered as confidential data. 
2- Tool development:

After reviewing of national and international literatures, this review was a guide for developing students' opinion scale and for adapting students' performance evaluation scale .

\section{3-Validity and reliability of tools}

A pilot study conducted on group of five master students registers in specialty semester of community health nursing and had previous experience with PBL to test the content validity of the study tools. Based on the finding of the pilot study, modifications were made to the tools.

The reliability was tested by statistical SPSS package to yield a Cronbach's alpha of 0.94 .

\section{4- Designing and implementation of the PBL module:}

-The researchers designed the mentioned course by using a hybrid model of PBL to fit to the level of the master students. A timetable of 24 contacts hours over 12 weeks was carried out. This duration was one class for 2 hours/ week. The researchers participated in running the sessions and dividing students into groups.

-Students were divided into 9 groups of 7-8 master students. The nine trigger scenarios were assigned randomly to the groups. Three scenarios were assigned for each researcher who played the facilitator role. Each group was directly exposed to one trigger scenario for four weeks and indirectly to 8 trigger scenarios as audiences over the remaining four weeks.

- The first week included two sessions. The first session started with introduction to the community health and the concepts of problem-based learning for two hours. Then role-play was used to orient students about the problem- based learning process. The second session focused on the basic principles of library utilization and database search for 1 hour.

- The second week included the first tutorial hour that was spent on introducing the triggers scenarios to the students. Each group worked to explore the learning issues of the scenario and select a team leader to acquire the leadership and communication skills. The researchers helped postgraduate students to establish the ground rules and to identify the responsibility of each member in the group work. In addition, they formulate a readable format and presentation of their discussions.

- During the third and fourth weeks, one hour/ week was allocated for self- study and group independent discussion. Each group had a compulsory weekly one tutorial hour to check that students' response to the course and to assess their PBL activities. During the compulsory tutorial hour, students were asked to illustrate their decisions about their goals and learning objectives as well as their plan to achieve these objectives. Moreover, researchers provided tutorial advice for master students as they need at any time.

-At the fifth week, each group was asked to observe a community setting to correlate the obtained knowledge from the trigger scenario with the real community to be mentioned in their final presentations.

-During the sixth week up to the eighth week, each group presented their conclusion about the assigned trigger scenario in 15-20 minutes. The presenter group was asked questions by audiences and tutors and comments were recorded. At the ninth week up to the twelfth week, postgraduate students presented a final conclusion to all students.

\section{5- Data collection:}

-The tutorial and peer evaluation during the course was done. This evaluation depended on the objectives that were planned to be covered in each session. Evaluation also included the steps that the groups were working on during the previous PBL sessions. Students' scores were obtained every tutorial meeting and were summed at the end of the course.

- Self-evaluation and students' opinion took place by the end of the course the. Self- evaluation and students' opinion were used to permit students to reflect on their abilities, performance, and personal characteristics.

\section{6- Data analysis:}

The data was analyzed by using SPSS (Stand for statistical product and service solution) program version 16 . Person Chi Square and independent $t$ - test was used to find the difference between the level of tutorial evaluation and students self- evaluation.

\section{Results}

Table (1) illustrates the tutorial evaluation of postgraduate students' performance during PBL sessions. More than one third $(42.6 \%)$ of students showed very good level of performance in relation to reading of documented sources and $30.9 \%$ of them applied the acquired knowledge to the problem. Regarding to clinical reasoning and decision-making, $44.1 \%$ of postgraduate students discriminated the important information of the problem and formulated conclusion by very good level of performance. Self-directed learning skills included very good level of performance related to defining of learning objectives among $52.9 \%$ of postgraduate students. In addition to $45.6 \%$ showed very good level of performance in accomplishment of learning objectives. As regards to collaborative work, $50 \%$ of the postgraduate students showed very good level of performance towards achievement of the group's learning goals. Regarding attitude during discussion, $41.2 \%$ and $36.3 \%$ of them 
accepted feedback with openness and reacted positively to feedback and criticism by very good level, respectively.

Table (2) reveals the self-evaluation of postgraduate students' performance during PBL sessions. Half of participants $(50 \%)$ were able to obtain adequate information about the problem. Regarding clinical reasoning and decision making skills, $51.5 \%$ of them showed very good level of performance in relation to prioritizing and interpreting the given information in the problem. Regarding self-directed learning skills very good level of performance was achieved among $47.1 \%$ and $44.1 \%$ of students in identifying areas of opportunity for improvement and setting goals and establishing a concrete action plan to achieve their learning needs, respectively. Concerning to collaborative work, more than one-third $(33.8 \%)$ showed very good level of performance towards the attainment of the team's learning objectives. While $45.6 \%$ of students were able to discuss a topic and stand up for their point of view, they showed responsibility and commitment in all the assigned tasks by very good level of performance.

Table (3) represents the difference between tutorial evaluation and postgraduate self-evaluation for their acquired skills. There was significant difference $(\mathrm{P} \leq 0.05)$ between tutor evaluation and students' selfevaluation in all acquired skills items except self- directed learning skills did not show significant difference. The significant mean difference between valuation and postgraduate self-evaluation induced by increased selfevaluation scores in building of knowledge Base, collaborative work, and attitude during discussion skills as well as the overall scores of the acquired skills.

Table (4) shows peer-evaluation results of postgraduate students' performance during PBL sessions. Regarding postgraduate students' attitude in class $50 \%$ of students were prepared for every class, open to criticism and accepted feedback openly. More than half of them (54.4\%) showed responsibility and commitment by very good level of performance. Regarding their attitudes toward collaborative work, $51.5 \%$ of them showed very good level in attendance of every group meeting. Moreover, $48.5 \%$ worked towards achievement of the group's learning objectives, $52.9 \%$ listened to their classmates and $45.6 \%$ showed responsibility and commitment in all the team's tasks.

Table (5) clarifies the opinion of postgraduate students regarding PBL sessions. More than half (54.4\%) of postgraduate students strongly agreed that they became able to utilize the library and $52.9 \%$ of them strongly agreed that, they became able to utilize internet. While $33.8 \%$ and $54.4 \%$ of students strongly agreed that, they discovered their talent and acquired problem-solving skills, respectively. Regarding learning methods, $83.8 \%$ of them strongly agreed that PBL is more effective than lecture. While, $88.2 \%$ of postgraduate students strongly agreed that the internet is the most common source that add recent information and the library is the second information source. As regards to the acquired skills, $63.2 \%$ of postgraduate students strongly agreed that they acquired teamwork skills and $41.2 \%$ of them strongly agreed that they acquired collaborative skills. Postgraduate students strongly agreed that tutorial time was adequate $(39.7 \%)$, and they had opportunity to express their opinion $(38.2 \%)$.

Table (1): Distribution of Post graduate students according to the tutor's evaluation of their performance' throughout problem-based learning sessions.

\begin{tabular}{|c|c|c|c|c|c|c|c|c|c|c|c|c|}
\hline Acquired Skills & $\begin{array}{l}\begin{array}{l}\text { Not } \\
\text { dereloped }\end{array} \\
\end{array}$ & $\%$ & Poor & 96 & Fair & 96 & Good & 96 & $\begin{array}{l}\text { Very } \\
\text { Good }\end{array}$ & 96 & Excellent & 96 \\
\hline \multicolumn{13}{|l|}{ Building of knowled ge base } \\
\hline -Show evidence by reading of documented sources & 0 & 0 & 1 & 1.5 & 9 & 13.2 & 26 & 38.2 & 29 & 42.6 & 3 & 1.5 \\
\hline -Shows breadith and depth of lnowlidge about tha problem & & 1.5 & 0 & 0 & 11 & 16.2 & 35 & 51.5 & 14 & 28.6 & & 10.3 \\
\hline -Shares own opinions without reading notes books. & $\frac{1}{0}$ & 0 & 0 & 0 & $\frac{11}{11}$ & $\frac{10.2}{16.2}$ & 30 & $\frac{\pi .3}{44.1}$ & 18 & 26.0 & 9 & $\frac{10.3}{13.2}$ \\
\hline \multirow{2}{*}{\multicolumn{13}{|c|}{ Clinical reasoning and decision making }} \\
\hline & & & & & & & & & & & & \\
\hline -Discriminates important information of the problem & 1 & 1.5 & 0 & 0 & 4 & 5.9 & 28 & 41.1 & 30 & 44.1 & 5 & 7.4 \\
\hline Prioritizas the information & 0 & 0 & 1 & 1.5 & 6 & 8.8 & 25 & 36.8 & 27 & 39.7 & 9 & 13.2 \\
\hline 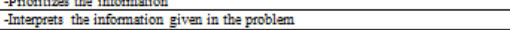 & 0 & 0 & $\frac{1}{0}$ & $\frac{1.3}{0}$ & $\frac{0}{9}$ & $\frac{8.8}{13.2}$ & 25 & $\frac{3.8}{36.8}$ & 29 & $\frac{3.1}{42.6}$ & $\frac{9}{5}$ & $\frac{15.2}{7.4}$ \\
\hline - dacision making basad on evidence & 0 & 0 & 0 & 0 & 10 & 14.7 & 29 & 42.6 & 23 & 33.8 & 6 & \\
\hline -Fomulates conclusion & 1 & 1.5 & 0 & 0 & 5 & 7.4 & 19 & 27.9 & 30 & 44.1 & 4 & 5.9 \\
\hline \multicolumn{13}{|l|}{ Self - Directed learning } \\
\hline & 0 & 0 & 0 & 0 & 1 & 1.5 & 18 & 26.5 & 36 & 52.9 & 13 & 19.1 \\
\hline -Shows evidence of accomplishment of leasning objectives & 0 & 0 & 1 & 1.5 & 0 & 0 & 38 & 55.8 & 31 & 45.6 & 3 & 4.4 \\
\hline -Shows evidence of reading diverse and recent bibliographic sources & 0 & 0 & 1 & 1.5 & 3 & 4.4 & 29 & 42.6 & 30 & 44.1 & 5 & 7.4 \\
\hline & 1 & 1.5 & 0 & 0 & 1 & 1.5 & 28 & 41.2 & 27 & 39.7 & 10 & 14.7 \\
\hline -Seolss coumseling to orient study & 0 & 0 & 1 & 1.5 & 3 & 4.4 & 26 & 38.2 & 29 & 42.6 & 9 & 13.2 \\
\hline -Dives him herself to the limits of his/her knowldige and abilities & 0 & 0 & 1 & 1.5 & 3 & 4.4 & 35 & 51.5 & 29 & 42.6 & 10 & 14.7 \\
\hline -Identifies his har opportunity areas & 0 & 0 & 0 & 0 & 3 & 4.4 & 28 & 41.2 & 26 & 38.2 & 11 & 16.2 \\
\hline $\begin{array}{l}\text {-Establishes leaming gools and defines a concrete action plan to meat leaming } \\
\text { naxds }\end{array}$ & 1 & 1.5 & 0 & 0 & 1 & 1.5 & 33 & 48.5 & 29 & 42.6 & 4 & 5.9 \\
\hline \multicolumn{13}{|l|}{ Collaborative Work } \\
\hline -Works towards achievement of the group's laaming goals & 0 & 0 & 0 & 0 & 2 & 2.9 & 19 & 27.9 & 34 & 50 & 13 & 19.1 \\
\hline -Shows effative interpersonal abilities & 0 & 0 & 0 & 0 & 4 & 5.9 & 30 & 44.1 & 24 & 35.3 & 10 & 14.7 \\
\hline -Participates in deily discoussion & 0 & 0 & 0 & 0 & 6 & 8.8 & 26 & 38.5 & 23 & 33.8 & 13 & 19.1 \\
\hline -Shares bibliographic sources with classmates & 0 & 0 & 1 & 1.5 & 5 & 7.4 & 24 & 35.3 & 23 & 33.8 & & 1.5 \\
\hline -Respects classmates' opirions & 1 & 1.5 & 0 & 0 & 4 & 5.9 & 31 & 45.6 & 17 & 25 & 15 & 22.1 \\
\hline -Halps classmates who lag behind & 1 & 1.5 & 0 & 0 & 1 & 1.5 & 32 & 47.1 & 21 & 30.9 & 13 & 19.1 \\
\hline -Gives feadback in a constructive way & 1 & 1.5 & 0 & 0 & 3 & 4.4 & 28 & 41.2 & 24 & 35.3 & 12 & 17.6 \\
\hline -Works as hard as the rest of his teammattes & 0 & 0 & 1 & 1.5 & 2 & 2.9 & 26 & 38.2 & 22 & 32.4 & 17 & 25 \\
\hline \multicolumn{13}{|l|}{ Attitude during discussion } \\
\hline -Accepts faschasck with openness & 1 & 1.5 & 0 & 0 & 1 & 1.5 & 20 & 29.4 & 28 & 41.2 & 18 & 26.5 \\
\hline -Raacts positivaly to fasbacks and criticism & 0 & 0 & 1 & 1.5 & 2 & 2.9 & 222 & 32.4 & 25 & 36.8 & 18 & 26.5 \\
\hline -Nanagas hish her impulsiveness adaquately & 0 & 0 & 1 & 1.5 & 2 & 2.9 & 29 & 42.6 & 23 & 33.8 & 13 & 19.1 \\
\hline -Stands up for his her points of view & 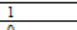 & 1.5 & 0 & 0 & 0 & 0 & 32 & 47.1 & 18 & 26.5 & 17 & \\
\hline -Makes an effort to adaquate his her bohasvior to circumstances & 0 & 0 & 0 & 0 & 2 & 2.9 & 21 & 30.9 & 21 & 30.9 & 16 & 23.5 \\
\hline $\begin{array}{l}\text {-Shorws ability to change his her point of view in light of new information given } \\
\text { or obtainad. }\end{array}$ & 0 & 0 & 1 & 1.5 & 2 & 2.9 & 30 & 44.1 & 23 & 33.8 & 12 & 17.6 \\
\hline -Attendad every class and arrivad on tima & 0 & 0 & 4 & 5.9 & 10 & 14.7 & 18 & 26.5 & 19 & 27.9 & 17 & 25 \\
\hline -Shows responsibility and commitment & 0 & 0 & 1 & 1.5 & 1 & & 26 & 38.2 & 15 & 22.1 & 25 & $\frac{36.8}{6.5}$ \\
\hline -Honest & 1 & 1.5 & 0 & 0 & 1 & 1.5 & 15 & 10.3 & 16 & 23.5 & 35 & 51.5 \\
\hline -Apparance and clothing correspond with that of a madical professional. & 1 & 1.5 & 0 & 0 & 0 & 0 & 8 & 11.2 & 12 & 17.6 & 48 & 70.6 \\
\hline
\end{tabular}


Table (2): Distribution of Post graduate students according to self-evaluation of their performance' throughout problem-based learning sessions.

\begin{tabular}{|c|c|c|c|c|c|c|c|c|c|c|c|c|}
\hline Acquired Skills & $\begin{array}{l}\text { Not } \\
\text { developed }\end{array}$ & $\%$ & Poor & $\%$ & Fair & $\%$ & Good & $\%$ & $\begin{array}{l}\text { Very } \\
\text { Good }\end{array}$ & $\%$ & Excellent & $\%$ \\
\hline \multicolumn{13}{|l|}{ Building of Knowledge Base } \\
\hline - I am able to obtain adequate information about the problem & 0 & 0 & 1 & 1.5 & 4 & 5.9 & 16 & 23.5 & 34 & 50 & 13 & 19.1 \\
\hline - comprehend the information & 0 & 0 & 1 & 1.5 & 2 & 2.9 & 23 & 33.8 & 21 & 30.9 & 21 & 30.9 \\
\hline - I am cable of applying concapts & 0 & 0 & 1 & 1.5 & 6 & 8.8 & 21 & 30.9 & 23 & 33.8 & 17 & 25 \\
\hline \multicolumn{13}{|l|}{ Clinical Rea soning and Decision-Making skills } \\
\hline - I am able to identify the us eful information in the problem & 0 & 0 & 0 & 0 & 5 & 7.4 & 15 & 22.1 & 29 & 42.6 & 19 & 27.9 \\
\hline -1 am able to prioritize the information. & 0 & 0 & 0 & 0 & 3 & 4.4 & 14 & 20.6 & 35 & 51.5 & 16 & 23.5 \\
\hline - I am able to interpret (give significance) the information given in the problem. & 0 & 0 & 2 & 2.9 & 2 & 2.9 & 12 & 17.6 & 35 & 51.5 & 17 & 25 \\
\hline - I am able to support my clinical reas oning and decision making with evidence & 0 & 0 & 1 & 1.5 & 4 & 5.9 & 13 & 19.1 & 32 & 47.1 & 18 & 26.5 \\
\hline -1 showed evidence and understanding of critical facts & 0 & 0 & 2 & 2.9 & 4 & 5.9 & 27 & 39.7 & 20 & 29.4 & 15 & 22.1 \\
\hline -1 was able to formulate conclusions about the problem & 0 & 0 & 1 & 1.5 & 2 & 2.9 & 17 & 25 & 27 & 39.7 & 21 & 30.9 \\
\hline \multicolumn{13}{|l|}{ Self - Directed learning } \\
\hline Is showed evidence of accomplishment of the learning objectives & 1 & 1.5 & 0 & 0 & 5 & 7.4 & 26 & 38.6 & 23 & 33.8 & 13 & 19.1 \\
\hline - I showed evidence of reading diverse and recent bibliographic sources & 0 & 0 & 0 & 0 & 7 & 10.3 & 22 & 32.4 & 18 & 26.5 & 21 & 30.9 \\
\hline I made efforts to improve. & 0 & 0 & 0 & 0 & 3 & 4.4 & 15 & 22.1 & 25 & 36.8 & 25 & 36.8 \\
\hline -If necessary, I asked for counseling to orient my study & 0 & 0 & 1 & 1.5 & 0 & 0 & 11 & 16.2 & 27 & 39.7 & 29 & 42.6 \\
\hline-1 pushed myself to the limits of my knowledge and abilities. & 0 & 0 & 1 & 1.5 & 2 & 2.9 & 10 & 14.7 & 28 & 41.2 & 27 & 39.7 \\
\hline - identified my areas of opportunity for improvement. & 0 & 0 & 1 & 1.5 & 1 & 1.5 & 14 & 20.6 & 32 & 47.1 & 20 & 29.4 \\
\hline -I set goals and established a concrete action plan to achieve my learning needs & 0 & 0 & 1 & 1.5 & 2 & 2.9 & 14 & 20.6 & 30 & 44.1 & 21 & 30.9 \\
\hline \multicolumn{13}{|l|}{ Collaborative work } \\
\hline -1 worked towards the attainment of the team's learning objectives & 1 & 1.5 & 0 & 0 & 2 & 2.9 & 17 & 25 & 23 & 33.8 & 25 & 36.8 \\
\hline -1 showed effective interpers onal skills. & 1 & 1.5 & 0 & 0 & 4 & 5.9 & 17 & 25 & 26 & 38.2 & 20 & 29.4 \\
\hline I was always eager to participate in discussions. & 1 & 1.5 & 2 & 2.9 & 5 & 7.4 & 12 & 17.6 & 22 & 32.4 & 26 & 38.2 \\
\hline -1 shared bibliographic sources with my classmates & 0 & 0 & 3 & 4.4 & 3 & 4.4 & 17 & 25 & 23 & 33.8 & 22 & 32.4 \\
\hline - participated in all group activities & 0 & 0 & 1 & 1.5 & 7 & 10.3 & 14 & 20.6 & 25 & 36.8 & 21 & 30.9 \\
\hline I attended on time every team meeting and fulfilled my assignments & 0 & 0 & 2 & 2.9 & 5 & 7.4 & 15 & 22.1 & 24 & 35.3 & 22 & 32.4 \\
\hline I showed responsibility and commitment in all the team's tasks & 1 & 1.5 & 1 & 1.5 & 2 & 2.9 & 17 & 25 & 22 & 32.4 & 25 & 36.8 \\
\hline -1 respected other people's opinion. & 0 & 0 & 1 & 1.5 & 3 & 4.4 & 6 & 8.8 & 23 & 33.8 & 35 & 51.5 \\
\hline Thelped clas smates who lagged behind. & 0 & 0 & 1 & 1.5 & 0 & 0 & 11 & 16.2 & 29 & 42.6 & 27 & 39.7 \\
\hline - offered feedback to my classmates in a constructive, friendly way. & 0 & 0 & 1 & 1.5 & 5 & 7.4 & 9 & 13.2 & 24 & 35.3 & 29 & 42.6 \\
\hline -I worked as hard as the group. & 0 & 0 & 1 & 1.5 & 2 & 2.9 & 23 & 33.8 & 16 & 23.5 & 26 & 38.2 \\
\hline \multicolumn{13}{|l|}{ Attitude during discussion } \\
\hline I was able to discuss a topic and stand up for my point of view & 1 & 1.5 & 0 & 0 & 2 & 2.9 & 18 & 26.5 & 31 & 45.6 & 16 & 23.5 \\
\hline I attended every class and arrived on time. & 1 & 1.5 & 0 & 0 & 4 & 5.9 & 12 & 12 & 21 & 30.9 & 30 & 44.1 \\
\hline - I studied and prepared for every class. & 0 & 0 & 1 & 1.5 & 6 & 8.8 & 19 & 27.9 & 21 & 30.9 & 21 & 30.9 \\
\hline Idid my best effort in each class and assignment & 0 & 0 & 2 & 2.9 & 1 & 1.5 & 17 & 25 & 25 & 36.8 & 23 & 33.8 \\
\hline -I was always eager to participate in the tutorial discussion. & 0 & 0 & 1 & 1.5 & 5 & 7.4 & 13 & 19.1 & 30 & 44.1 & 19 & 27.9 \\
\hline Thanded my work on time. & 0 & 0 & 1 & 1.5 & 5 & 7.4 & 14 & 20.6 & 26 & 36.2 & 22 & 32.4 \\
\hline -1 showed responsibility and commitment in all the as signed tasks... & 0 & 0 & 1 & 1.5 & 3 & 4.4 & 9 & 13.2 & 31 & 45.6 & 24 & 35.3 \\
\hline - w was open to criticism and reacted favorably & 0 & 0 & 3 & 4.4 & 3 & 4.4 & 13 & 19.1 & 30 & 44.1 & 19 & 27.9 \\
\hline - I used feedback to improve my attitudes. & 0 & 0 & $T$ & 1.5 & 3 & 4.4 & 12 & 17.6 & 25 & 36.8 & 27 & 39.7 \\
\hline - am able to identify my strength and opportunity areas. & 0 & 0 & 1 & 1.5 & 2 & 2.9 & 11 & 16.2 & 31 & 45.6 & 23 & 33.87 \\
\hline -My appearance and clothing correspond with that of a medical professional. & 0 & 0 & 2 & 2.9 & 1 & 1.5 & 7 & 10.3 & 29 & 42.6 & 29 & 42.6 \\
\hline
\end{tabular}

Table (3): Difference between tutorial evaluation and Post graduate students self-evaluation.

\begin{tabular}{|c|c|c|c|}
\hline Acquired Skills & $\begin{array}{l}\text { Tutor } \\
\text { evaluation } \\
\wp \pm \text { S.D }\end{array}$ & $\begin{array}{ll}\begin{array}{l}\text { Students' } \\
\text { evaluation }\end{array} & \text { self- } \\
\wp \pm \text { S.D } & \\
& \\
\end{array}$ & $\begin{array}{l}\text { Difference } \\
\%\end{array}$ \\
\hline Building of Knowledge Base (Sores=) & 15.5 & 19.4 & \multirow[t]{3}{*}{25.2} \\
\hline T- test & \multicolumn{2}{|l|}{4.4} & \\
\hline $\mathrm{P}$ & \multicolumn{2}{|l|}{0.000} & \\
\hline $\begin{array}{l}\text { Clinical Reasoning and Decision- } \\
\text { Making skills (Sores=) }\end{array}$ & 27.8 & 24.4 & \multirow[t]{3}{*}{-12.2} \\
\hline T- test & \multicolumn{2}{|l|}{2.3} & \\
\hline $\mathrm{P}$ & \multicolumn{2}{|l|}{0.018} & \\
\hline Self - Directed learning (Sores=) & 33.0 & 34.8 & \multirow[t]{3}{*}{5.4} \\
\hline T- test & \multicolumn{2}{|l|}{1.0} & \\
\hline $\mathrm{P}$ & \multicolumn{2}{|l|}{0.29} & \\
\hline Collaborative work (Sores $=$ ) & 34.2 & 54.8 & \multirow[t]{3}{*}{60.2} \\
\hline T- test & \multicolumn{2}{|l|}{10.1} & \\
\hline $\mathrm{P}$ & \multicolumn{2}{|l|}{0.000} & \\
\hline Attitude during discussion (Sores= ) & 44.0 & 54.8 & \multirow[t]{3}{*}{24.5} \\
\hline T- test & \multicolumn{2}{|l|}{4.6} & \\
\hline $\mathrm{P}$ & \multicolumn{2}{|l|}{0.000} & \\
\hline Total evaluation (Sores $=$ ) & 154.5 & 188.3 & \multirow[t]{3}{*}{21.8} \\
\hline T- test & \multicolumn{2}{|l|}{4.1} & \\
\hline $\mathrm{P}$ & \multicolumn{2}{|l|}{0.00} & \\
\hline
\end{tabular}

Table (4): Distribution of Post graduate students according to the peer evaluation of their performance' throughout problem-based learning sessions.

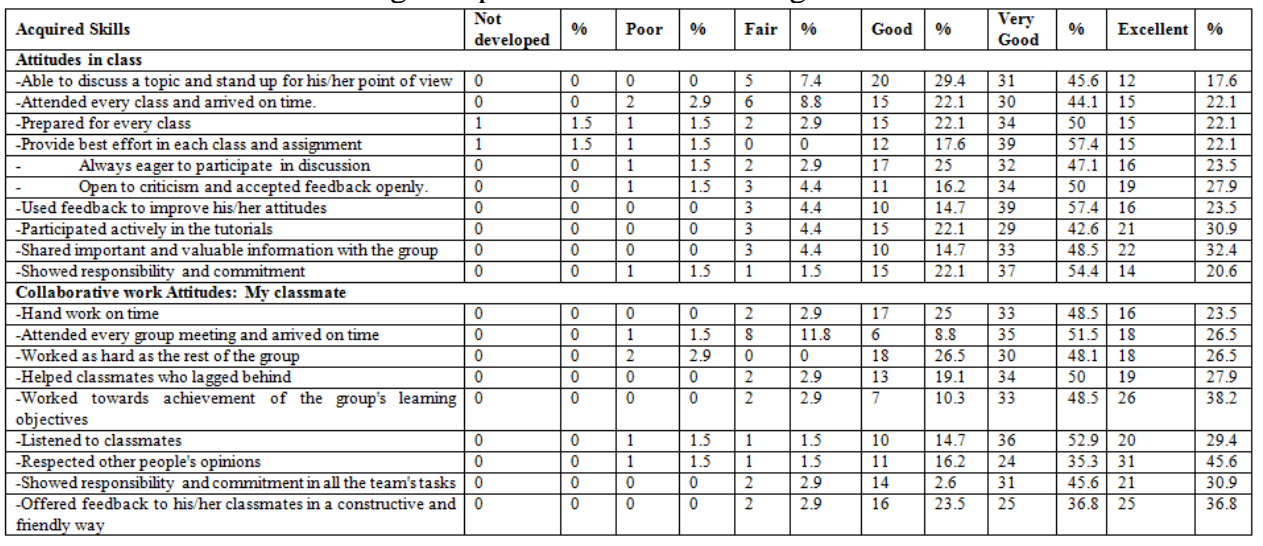


Table (5): Distribution of Post graduate students according to their opinion regarding problem-based learning sessions.

\begin{tabular}{|c|c|c|c|c|c|c|c|c|c|c|}
\hline Problem-based learning help Post graduate students to & Agree & $\%$ & $\begin{array}{l}\text { Strongly } \\
\text { agree }\end{array}$ & $\%$ & Neutral & $\%$ & Disagree & $\%$ & \begin{tabular}{|l} 
Strongly \\
Disagree
\end{tabular} & $\%$ \\
\hline -Gain information & 42 & 61.8 & 23 & 33.8 & 3 & 4.4 & 0 & 0 & 0 & 0 \\
\hline -Utilize the information & 24 & 35.3 & 39 & 57.4 & 3 & 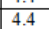 & 1 & 1.5 & \begin{tabular}{|c|c|}
1 \\
\end{tabular} & 1.5 \\
\hline -Utilize the library & 23 & 33.8 & 37 & 54.4 & 8 & \begin{tabular}{|l|l}
11.8 \\
\end{tabular} & 0 & 0 & 0 & 0 \\
\hline -Utilize the intemet & 23 & 33.8 & 36 & 52.9 & 8 & 11.8 & 1 & 1.5 & 0 & 0 \\
\hline -Discover his/her talents & 33 & 48.5 & 23 & 33.8 & 10 & \begin{tabular}{|l|l|}
14.7 & \\
\end{tabular} & 2 & 2.9 & 0 & 0 \\
\hline -Discover the others talents & 27 & 39.7 & 27 & 39.7 & 11 & 16.2 & 2 & 2.9 & 0 & 0 \\
\hline -Acquire problem solving skills & 26 & 38.2 & 37 & 54.4 & 3 & 4.4 & 1 & 1.5 & 1 & 1.5 \\
\hline -Work with a team & 32 & 47.1 & 27 & 39.7 & 7 & 10.3 & 2 & 2.9 & 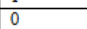 & 0 \\
\hline -Be a team leader & 36 & 52.9 & 25 & 36.8 & 6 & 8.8 & 1 & 1.5 & 0 & 0 \\
\hline \multicolumn{11}{|l|}{ Post graduate students Views about PBL as: } \\
\hline \multicolumn{11}{|l|}{ Effective learning method } \\
\hline -Improve leaming & 10 & 14.7 & 53 & 77.9 & 3 & 4.4 & 1 & 1.5 & 1 & 1.5 \\
\hline -Exchange ideas and knowledge & 10 & 14.7 & 53 & 77.9 & 3 & 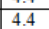 & \begin{tabular}{|ll}
1 \\
\end{tabular} & 1.5 & \begin{tabular}{|lll}
1 \\
1
\end{tabular} & 1.5 \\
\hline -Effective than lecture & 7 & 10.3 & 57 & 83.8 & 2 & 2.9 & 1 & 1.5 & 1 & 1.5 \\
\hline \multicolumn{11}{|l|}{ Facilities resources PBL } \\
\hline - Intemet is the commonest source added recent information. & 5 & 7.4 & 60 & 88.2 & 3 & 4.4 & 0 & 0 & 0 & 0 \\
\hline - Library is the second information source. & 5 & 7.4 & 60 & 88.2 & 3 & 4.4 & 0 & 0 & 0 & 0 \\
\hline The previous studies used & 35 & 51.5 & 25 & 36.7 & 6 & 8.8 & 1 & 1.5 & 1 & 1.5 \\
\hline \multicolumn{11}{|l|}{ Acquired skills } \\
\hline -Team work skills & 20 & 29.4 & 43 & 63.2 & 3 & 4.4 & 1 & 1.5 & 1 & 1.5 \\
\hline -Collaborative skills & 30 & 44.1 & 28 & 41.2 & 8 & 11.8 & 1 & 1.5 & 1 & 1.5 \\
\hline -Creativity skills & 25 & 36.7 & 33 & 48.5 & 6 & 8.8 & 2 & 2.9 & 2 & 2.9 \\
\hline \multicolumn{11}{|l|}{ Provided resources and tutorial support } \\
\hline -Adequate tutorial Time & 32 & 47.1 & 27 & 39.7 & 8 & 11.2 & 1 & 1.5 & 0 & 0 \\
\hline -Guidance & 32 & 47.1 & 29 & 42.6 & 7 & 10.3 & 0 & 0 & 0 & 0 \\
\hline -Opportunity to express their opinion & 33 & 48.5 & 26 & 38.2 & 9 & 12.3 & 0 & 0 & 0 & 0 \\
\hline - Clear Scenarios & 36 & 52.9 & 21 & 30.9 & 9 & 13.2 & 2 & 2.9 & 0 & 0 \\
\hline -No over lapping of meaning & 35 & 51.5 & 21 & 30.9 & 10 & 14.7 & 2 & 2.9 & 0 & 0 \\
\hline -Adequate time for each Scenario & 40 & 58.8 & 22 & 32.4 & 4 & 5.9 & $\frac{2}{2}$ & 2.9 & 0 & 0 \\
\hline -Leaming contents appropriate to each scenario & 34 & 50 & $\frac{22}{21}$ & 30.9 & 12 & 17.6 & $\frac{2}{1}$ & 1.5 & 0 & 0 \\
\hline - Bibliographies are available & 34 & 50 & 18 & 26.5 & 10 & 14.7 & 5 & 7.5 & 1 & 1.5 \\
\hline
\end{tabular}

\section{Discussion}

Quality in nursing practice depends upon educational preparation of nurses to solve problem, think critically, and make decisions in today's health care system ${ }^{(15,16)}$. Therefore, using problem based learning (PBL) is very important to empower students' work through a actively participating in the learning process, and identify learning goals with peers, engaging in self-study. PBL also empower students' skills through discussing and applying new learning strategy, and integrating a variety of knowledge ${ }^{(17)}$.

The current study revealed that more than two thirds of the postgraduate students strongly agreed that PBL is more effective educational strategy than the traditional methods. In addition, they showed very good level of performance in relation to interpret the information and attainment of the team's learning objectives. Around half of them showed responsibility and commitment in all the team's tasks and more than half reported they are strongly agree that they acquired team work skills. The same findings was found in Saudi Arabia ${ }^{(18)}$ study which reported that more than two thirds of participants agreed that PBL is better than the traditional system and helps in improving student skills mostly problem solving skills and help whetting analytic skills. Furthermore, it provides students with the skills of finding, assessing, and interpreting the evidence that are required to analyze a health condition. These skills lead to the proficient practice, which can be achieved by teamwork ${ }^{(19)}$.

Moreover, the results of this study showed improvement of learner abilities in self-directed learning, critical thinking, independent study, group interaction, reasoning skills, and active participation. The findings of this study was documented in different studies ${ }^{(20,21)}$ one conducted in nursing education in Community health nursing and the second one conducted in Critical care and emergency nursing both studies in Egypt. These studies revealed that PBL as a new teaching approach was preferred among the majority of undergraduate nursing students. In addition, they acquired critical thinking and group interaction skills.

On the other hand, a study was conducted in Sweden ${ }^{(22)}$ found that PBL is very motivating and enhances remembering of the learned issues. This finding is enrolled with the current study, which showed that postgraduate students are strongly agreed that PBL improve learning. Furthermore, they reported that they acquired problem solving skills as well as the ability to discover their own talent. This is in agreement with study conducted in china that found, PBL fostered critical thinking, problem solving skills and life-long learning skills that are obtained by students ${ }^{(23)}$.

Moreover, post graduate students utilized library and internet, they gained teamwork and collaboration skills. Concerning peer evaluation, more than half of students showed responsibility, commitment, attended every group meeting and listen to their classmate by very good level of performance. These results enrolled with study conducted in Australia on peer assessment of first year medical students, which revealed that peer assessment encourages students to develop critical reasoning skills and enable them to learn from each other. ${ }^{(24)}$

However, a study in China confirmed that students who are familiar with the traditional teaching might feel uncomfortable in PBL roles in which they have to coordinate with peers, be independent, and generate their own studying materials ${ }^{(25)}$. These was contradicted with the current study in which, the majority of postgraduate students who were familiar with the traditional teaching strongly agreed that PBL is effective than lecture. 


\section{Conclusion}

Postgraduate nursing students accept PBL as educational strategy. They found PBL a method that improves learning and positively affects students' skills. Application of PBL acquiring problem-solving skills and develops self-directed learning skills as well as computer skills through utilizing the internet. PBL enriched students with teamwork experience and developed their group collaboration skills.

\section{Recommendation}

This study recommended that PBL strategy should be applied in postgraduate community health nursing courses.

\section{References}

[1]. Barell, J. Problem-based learning: An inquiry approach. 2007; (2nd ed.). Thousand Oaks, CA: Corwin Press, Inc.

[2]. Oja, Kenneth, . Using problem-based learning in the clinical setting to improve nursing students' critical thinking: An evidence review. The Journal of Nursing Education.2011; 50(3): 145-151.

[3]. Yuan, H., Kunaviktikul, W., Klunklin, A. and Williams, B. A. Improvement of nursing students' critical thinking skills through problem-based learning in the People's Republic of China: A quasi-experimental study. Nursing and Health Sciences. 2008 ; 10 (1):70-76

[4]. Smith-G, Jeffrey W., Using Problem-Based Learning to Link Classroom and Clinical Education. Human Kinetics -ATT 2010;15(1): 23-27

[5]. Keshk L. I, Qalawa. S. A and Abd El-Azim.S(2016): Efficiency of Problem Based Learning Course at College of Nursing in Egypt and KSA: Comparative Study. American Journal of Educational Research; 2016; 4( 6): 450-458, Available online at http://pubs.sciepub.com/education/4/6/3 @ Science and Education Publishing. DOI:10.12691/education-4-6-3

[6]. Shahin .E.S \& Tork.H.M.. Critical thinking and self-directed learning as an outcome of problem-based learning among nursing students in Egypt and Kingdom of Saudi Arabia. Journal of Nursing Education and Practice.2013; 3(1): 12. ISSN 1925-4040 EISSN 1925-4059

[7]. Hagi, S. K., \& Al-Shawwa, L.A.. Evaluation of second and fourth year undergraduate medical students' perception and acceptance of the problem-based learning process. Saudi Med J.2011; 32, 1060-1065.

[8]. Sofie M. M. Loyens1, Paul A. Kirschner, \& Fred Paas. Problem-Based Learning. Research Online 2011.

[9]. Carlisle C. and Ibbotson Tracy: Introducing problem-based learning into research methods teaching: Student and facilitator evaluation. Nurse Education Today,25: 527-41, 2005.

[10]. Rogal M.S. and Sinder D.P.: Rethinking the lecture: The application of problem based learning methods to atypical contexts. Nurse Education in Practice, 8: 312-9, 2008.

[11]. Andis K, Heather H. Impact of problem-based learning in a large classroom setting: student perception and problem-solving skills. Advances in Physiology Education Published 1 December. 2011; 35 (4): 408-415.DOI: 10.1152/advan.00046.2011

[12]. National Authority for Quality Assurance and Accreditation of Education (NA QAA). National Academic Reference Standards (NARS) For Bachelor Degree of Nursing, 2008.

[13]. Schmidt, H. G., Vermeulen, L., and van der Molen, H. T. Long-term effects of problem-based learning: a comparison of competencies acquired by graduates of a problem-based and a conventional medical school. Med. Educ..2006; 40(6), 562-567.

[14]. Montemayor, L.E. Formative and summative assessment of the problem based tutorial session using a Criterion-Referenced System. JIAMSE 2004; 14, 8-14.

[15]. Walshe N, O’Brien S, Murphy S, Hartigan I,. Integrative Learning Through Simulation and Problem-Based Learning.2013;9: 4748.

[16]. Eman S. S, Hanan, M. Critical thinking and self-directed learning as an outcome of problem-based learning among nursing students in Egypt and Kingdom of Saudi Arabia. Journal of Nursing Education and Practice. 2013; 3 (12):103-110 Tork2.www.sciedu.ca/jnep

[17]. Gabr, H; Mohamed, N. Effect of Problem based learning on undergraduate nursing students enrolled in nursing administration course, International Journal of Academic Research.2011; 3 (1): 154

[18]. Shamsan B, Syed A.Evaluation of Problem Based Learning Course at College of Medicine, Qassim University, Saudi Arabia International Journal of Health Sciences, Qassim University.2009; 3(2): 249-258.

[19]. Callister, L.C., Matsumura, G., Lookinland, S., Mangum, S.,Loucks, C. Inquiry in baccalaureate nursing education: fostering evidence-based practice. Journal of nursing Education.2005; 44 (2): 59-64

[20]. SAMER E. ABD EL-RAOUF, AMEL I. AHMED. Med. J. Cairo Univ. Nursing Students' Experiences with Problem Based Learning: A Teaching Strategy Applied in Community Health Course. Med. J. Cairo Univ. 2014,79(1); 323-333

[21]. Sahar Y O, Samah A S . Students' Perception and Acceptance of Problem-based Learning Approach in Critical Care Nursing Practice. Scientific Cooperation International Workshops on Medical Topics, Ankara-TURKEY.2014; 52-67

[22]. Bengtsson M. Ohlsson B. The nursing and medical students motivation to attain knowledge Sweden. Nurse Education Today. 2010;30: 150-6.doi: 10.1016/j.nedt.2009.07.005.

[23]. Chouh.F. Chic C.: Experience of problem-based learning in nursing education at Kaohsiung medical university. Kaohsiung J. Med. Sci.2009; 25: 258-63.

[24]. Tracey P, Louise Y., Michele G. Peer Assessment in Problem -Based Learning: A Qualitative Study Advances in Health Sciences Education. 2007; 12:169-186

[25]. Yuans H., Williams A.B., Yinl., Liu M., Fang B.J. and Pangd. Nursing students' views on the effectiveness of problem-based learning China. IN Press Nurse Education Today.2010; dio: 10.1016/j.nedt. 2010. diol 10.009, 2010. 